\title{
Reduced HIV-1 latent reservoir outgrowth and distinct immune correlates among women in Rakai, Uganda
}

\author{
Jessica L. Prodger, ${ }^{1,2,3}$ Adam A. Capoferri, ${ }^{3}$ Katherine Yu, ${ }^{2}$ Jun Lai, ${ }^{3}$ Steven J. Reynolds, $, 3,4,5$ \\ Jingo Kasule, ${ }^{5}$ Taddeo Kityamuweesi, ${ }^{5}$ Paul Buule, ${ }^{5}$ David Serwadda, ${ }^{5,6}$ Kyungyoon J. Kwon, ${ }^{3}$ \\ Katherine Schlusser, ${ }^{3}$ Craig Martens, ${ }^{7}$ Eileen Scully, ${ }^{3}$ Yun-Hee Choi, ${ }^{2}$ Andrew D. Redd, ${ }^{3,4}$ \\ and Thomas C. Quinn ${ }^{3,4}$ \\ 'Department of Microbiology and Immunology and 'Department of Epidemiology and Biostatistics, Schulich School of \\ Medicine and Dentistry, Western University, London, Ontario, Canada. ${ }^{3}$ Division of Infectious Diseases, Johns Hopkins \\ University School of Medicine, Baltimore, Maryland, USA. ${ }^{4}$ Laboratory of Immunoregulation, Division of Intramural \\ Research, National Institute of Allergy and Infectious Diseases, NIH, Bethesda, Maryland, USA. ${ }^{5}$ Rakai Health Sciences \\ Program, Kalisizo, Uganda. ${ }^{6}$ Makerere University, Kampala, Uganda. ${ }^{7}$ Cenomic Unit, Rocky Mountain Laboratories, NIAID, \\ NIH, Hamilton, Montana, USA.
}

HIV-1 infection remains incurable owing to the persistence of a viral reservoir that harbors integrated provirus within host cellular DNA. Increasing evidence links sex-based differences in HIV-1 immune responses and pathogenesis; however, little is known about differences in HIV-1 infection persistence. Here, we quantified persistent HIV-1 infection in 90 adults on suppressive antiretroviral therapy in Rakai, Uganda ( 57 female patients). Total HIV-1 DNA was quantified by PCR, and replication-competent provirus by quantitative viral outgrowth assay (QVOA). Immune phenotyping of $\mathrm{T}$ cell subsets and plasma biomarkers was also performed. We found that whereas both sexes had similar total HIV DNA levels, female patients had significantly fewer resting CD4 ${ }^{+}$ cells harboring replication-competent virus, as measured by viral outgrowth in the QVOA. Factors associated with viral outgrowth differed by sex; notably, frequency of programmed cell death 1 $\left(\mathrm{PD}^{+}\right) \mathrm{CD}^{+} \mathrm{T}$ cells correlated with reservoir size in male but not female patients. The sex-based differences in HIV-1 persistence observed in this cohort warrant additional research, especially given the widespread use of the QVOA to assess reservoir size and current explorations of PD1 agonists in cure protocols. Efforts should be made to power future cure studies to assess outcomes in both male and female patients.

Conflict of interest: The authors have declared that no conflict of interest exists.

Copyright: () 2020, American Society for Clinical Investigation.

Submitted: April 17, 2020

Accepted: June 3, 2020

Published: July 23, 2020

Reference information: /CI Insight. 2020;5(14):e139287.

https://doi.org/10.1172/jici.

insight.139287.

\section{Introduction}

Globally, approximately 37.9 million people are living with HIV-1, with approximately two-thirds of infected individuals living in sub-Saharan Africa. HIV-1 remains incurable despite effective suppression of active viral replication by antiretroviral therapy (ART). This is owing to the persistence of a reservoir of stably integrated and replication-competent HIV-1 provirus, primarily in resting $\mathrm{CD} 4^{+} \mathrm{T}$ cells $(\mathrm{rCD} 4)$, which leads to viral rebound rapidly after ART cessation (1). This viral reservoir decays incredibly slowly, with a mean half-life of 44 months; therefore, people living with HIV-1 require lifetime use of ART $(2,3)$. The mechanisms that govern HIV-1 reservoir establishment and persistence are not fully understood; however, elucidating them will likely provide important insight for developing treatment modalities.

Little is known about the potential effect of biological sex on HIV-1 persistence. Today, females constitute approximately $52 \%$ of people living with HIV-1. Yet, despite being the fastest growing group of individuals infected with HIV-1, females represent only approximately $11 \%$ of the participants in HIV-1 cure studies (4). There is evidence that HIV-1 pathogenesis differs between the sexes. Compared with males, females have lower viral loads and per-cell HIV-1 RNA production during untreated infection, but faster rates of disease progression for a given viral load $(4,5)$. Additionally, females have different immunological responses to HIV-1 infection, including higher IFN- $\alpha$ production in response to HIV-1 RNA stimulation in vitro (6), elevated in vivo expression of IFN-stimulated genes (7), elevated $\mathrm{T}$ cell responses (8), decreased markers of immune 
exhaustion $(6,9)$, and altered immune biomarker responses to therapy (10). Previous studies of HIV-1 persistence have been limited, with 2 cross-sectional studies reporting that female participants had lower levels of $\operatorname{HIV}-\mathrm{DNA}(11,12)$ and 1 prospective study reporting lower levels of residual viremia and HIV-1 RNA production in female compared with male participants (9). Recent analysis of viral rebound kinetics among postpartum females suggested that females may be more likely than males to have prolonged time to viral rebound (13). Therefore, we sought to determine if reservoir size, and the clinical and immunological correlates of reservoir size, differed by sex in a well-matched cohort of people living with HIV-1 in Uganda.

\section{Results}

A total of $90 \mathrm{HIV}-1$-infected adults ( $\geq 18$ years), including 57 women and 33 men, were enrolled through the Rakai Health Sciences Program in Uganda (Table 1 and Supplemental Figure 1; supplemental material available online with this article; https://doi.org/10.1172/jci.insight.139287DS1). All participants had been virally suppressed on ART for at least 1 year, and all participants except for 1 were on first-line therapy (consisting of nucleoside and nonnucleoside reverse transcriptase inhibitors) (Table 1). The predominant HIV-1 subtype was D (women $=59.6 \%$, men $=54.5 \%)$, followed by subtype A $($ women $=15.8 \%$, men $=18.2 \%)$. Men and women were similar in age, pre-ART viral loads, nadir CD4 ${ }^{+} \mathrm{T}$ cell count, and duration of viral suppression. Men and women experienced transient viremia on ART with similar frequency and, for the subset with available data (women $=16$, men $=16$ ), had been infected with HIV for similar durations before ART initiation (median years: women $=6.1$, men $=5.6$ ). At the time of study entry, women had significantly higher $\mathrm{CD} 4{ }^{+} \mathrm{T}$ cell counts (median cells $/ \mu \mathrm{L}$ : women $=594$, men $\left.=458 ; P<0.01\right)$ and $\mathrm{CD}^{+} / \mathrm{CD}^{+}$ratios (median: women $=0.89$, men $=0.63 ; P<0.01$ ), despite similar nadir $\mathrm{CD}^{+} \mathrm{T}$ cell counts and time on ART. The most commonly reported hormonal contraception was Depo-Provera (18.8\%).

Immune phenotyping was performed by flow cytometry (T cells) and multiplexed ELISA (serum biomarkers). Most immune parameters were not significantly different between men and women; those that were significant are indicated in Table 1 . Female participants had significantly higher serum concentrations of D-dimer (273 vs. $130 \mathrm{ng} / \mathrm{mL}, P<0.01$ ), as previously reported (14), but similar concentrations of soluble markers previously associated with nonactivating T cell proliferation (IL-7 and IL-15) (15, 16), HIV-1 disease progression and non-AIDS mortality (sCD14, CRP, IL-6, IL-10, and IFN- $\alpha$ ) (17), and increased in vitro proviral integration (CXCL10, CXCL9, CCL20, and CCL19) (18).

Women and men were not significantly different in terms of overall $\mathrm{CD} 4^{+}$and $\mathrm{CD} 8^{+} \mathrm{T}$ cell frequencies; however, women had fewer effector memory CD4 ${ }^{+} \mathrm{T}$ cells $\left(\mathrm{CD} 28^{-} / \mathrm{CD} 4 \mathrm{RO}^{+} / \mathrm{CCR}^{-}, 1.88 \%\right.$ vs. $3.44 \%, P=$ $0.10)$ and $\mathrm{CD}^{+} \mathrm{T}$ cells producing IL-2 $(1.85 \%$ vs. $4.31 \%, P=0.08)$, although these differences did not reach statistical significance. Women and men had similar frequencies of activated (HLA-DR ${ }^{+} / \mathrm{CD} 38^{+}$and $\left.\mathrm{CD} 69^{+}\right)$, proliferating $\left(\mathrm{Ki}^{+} 7^{+}\right)$, and regulatory $\mathrm{CD}^{+} \mathrm{T}$ cells $\left(\mathrm{FoxP}^{+} / \mathrm{CD}^{2} 5^{+}\right)$, markers of $\mathrm{CD}^{+}$and $\mathrm{CD} 8^{+} \mathrm{T}$ cell exhaustion and senescence (PD1, Tim3, Lag3, and CD57), and effector functions (CD107a, IFN- $\gamma$, IL-2, and TNF).

Because approximately $90 \%$ of integrated HIV-1 provirus is defective (19), quantification of persistent HIV-1-infected cells was performed using quantitative PCR for a region of gag and the quantitative viral outgrowth assay (QVOA) for replication-competent virus. We found no significant correlation between these 2 estimates of reservoir size, in either men or women (women: $r=0.18, P=0.3$; men $r=-0.18$, $P=0.4$; Supplemental Figure 2). In contrast to the similarity in immunologic profiles, women had a significantly lower frequency of cells producing replication-competent virus ( 0.41 vs. 1.10 infectious units per million cells [IUPM], $P<0.01$ by nonparametric univariate analysis; Figure 1A). Reduced viral outgrowth from rCD4 in women was in contrast to total HIV DNA levels, which were not statistically significant between sexes (women $=2395$, men $=1200$ copies $/ 10^{6} \mathrm{rCD} 4, P=0.13$ by nonparametric univariate analysis; Figure 1B). The reduced viral outgrowth from $\mathrm{rCD} 4$ observed in women remained significant after controlling for clinical covariates $\left(\triangle \log _{10} \mathrm{IUPM}=0.53, P<0.01\right)$ and in a sensitivity analysis excluding observations with $\log _{10} \mathrm{IUPM}>1.0$ ( 3 men excluded; 0.41 vs. 0.98 IUPM, $P=0.02$ ).

We subsequently sought to identify demographic, clinical, and immune correlates of viral outgrowth from $\mathrm{rCD} 4$, as well as determine if correlates were different between sexes (Table 2). Based on univariate analysis, IUPM in women was negatively associated with age and duration of ART (both $P<0.01$ ), positively associated with $\mathrm{CD}^{+}$and $\mathrm{CD} 4^{+} \mathrm{T}$ cell effector functions (IL-2 and TNF, $P<0.05$ ), and although not reaching statistical significance, nadir $\mathrm{CD}^{+} \mathrm{T}$ cell count $(P=0.06)$. In contrast, IUPM in men was negatively associated with $\mathrm{CD} 4^{+} / \mathrm{CD}^{+} \mathrm{T}$ cell ratio $(P=0.01)$ and $\mathrm{CD} 8^{+} \mathrm{T}$ cell effector function (IL-2, $P=$ $0.02)$, and positively associated with $\mathrm{PD} 1$ expression on $\mathrm{CD}^{+} \mathrm{T}$ cells $(P=0.03)$. IUPM did not correlate 
Table 1. Clinical and immunological characteristics of HIV-1-positive Ugandan women and men

\begin{tabular}{|c|c|c|c|}
\hline Characteristic median (IQR) & Women $(n=57)$ & Men $(n=33)$ & $P$ value \\
\hline Age (yr) & $41.1(37.4,47.2)$ & $44.2(40.3,47.1)$ & 0.15 \\
\hline \multicolumn{4}{|l|}{ Subtype, $n$ (\%) } \\
\hline C & $1(1.8)$ & $1(3.0)$ & \\
\hline A & $9(15.8)$ & $6(18.2)$ & 0.83 \\
\hline Recombinant & $6(10.5)$ & $5(15.1)$ & \\
\hline Nadir CD4+ ${ }^{+}$cell count (cells $/ \mu \mathrm{L}$ ) & $180(109,232)$ & $168(129,238)$ & 0.92 \\
\hline Time on ART (yr) & $7.0(5.3,8.5)$ & 6.9 (3.3 9.3) & 0.86 \\
\hline $\begin{array}{l}\text { Proportion of viral loads }>400 \text { copies } / \mathrm{mL} \text {, } \\
\text { mean (range) }\end{array}$ & $0.005(0,0.118)$ & $0.003(0,0.059)$ & 0.93 \\
\hline Depo-Provera & $9(18.8)$ & & \\
\hline Birth control pills & $1(2.1)$ & & \\
\hline Levonorgestrel implants & $2(4.2)$ & & \\
\hline No hormonal & $8(16.7)$ & & \\
\hline \multicolumn{4}{|l|}{ Women ( $n=48) ;$ Men (n/a) } \\
\hline D-dimer $(n g / m L) ;$ women $(n=42)$, men $(n=20)$ & $273(198,534)$ & $130(80,219)$ & $<0.01$ \\
\hline $\begin{array}{l}\text { Effector memory CD4+ T cells (proportion); } \\
\text { women }(n=34) \text {, men }(n=12)\end{array}$ & $1.9(1.1,5.9)$ & $3.4(2.5,6.1)$ & 0.10 \\
\hline $\begin{array}{l}\text { IL-2 } 2^{+} \text {CD8 } 8^{+} \text {T cells (proportion); women }(n=34) \text {, } \\
\text { men }(n=13)\end{array}$ & $1.9(1.2,3.9)$ & $4.3(1.6,5.8)$ & 0.08 \\
\hline
\end{tabular}

with other immune parameters (Supplemental Tables 1-3) (including serum IL-7, CD4 ${ }^{+} \mathrm{T}$ cell memory subset distribution, activation, or proliferation) HIV-1 subtype, duration of untreated infection, or instances of transiently detectable viremia in either sex, or with hormonal contraception use by women.

To determine the most important contributors to reservoir size and to attempt to account for the interdependency of clinical variables, we constructed multivariable linear regression models independently for men and women using stepwise selection. Variables included in the stepwise regression were time on ART and pre-ART viral load (determined a priori from previous studies) $(1,20)$, as well as all variables associated with IUPM for that sex in univariate regression $(P<0.1)$ (Table 2 and Figure 2$)$. In women, this model identified pre-ART viral load $(P=0.01)$ and time since viral suppression $(P<0.01)$ as the most important predictors of IUPM. Production of TNF by $\mathrm{CD} 8^{+} \mathrm{T}$ cells also contributed to explaining variability in IUPM among women, although the association was not significant $(P=0.14)$. In men, time on ART was also found to be an important predictor of IUPM $(P=0.03)$; however, in contrast to women, immune outcomes were also identified as important predictors of IUPM. Among men, PD1 expression on CD4 ${ }^{+}$ T cells positively correlated with IUPM $(P=0.03)$, and production of IL-2 by CD8 ${ }^{+} \mathrm{T}$ cells negatively correlated with IUPM $(P=0.03)$.

\section{Discussion}

Based on the QVOA, an assay widely accepted for measurement of reservoir size, we found that Ugandan women have a reduced frequency of $\mathrm{rCD} 4$ containing replication-competent HIV-1 compared with their male peers. Interestingly, this was despite having similar frequencies of rCD4 containing HIV-1 DNA. These findings are consistent with a recent report from a North American cohort, which found evidence of lower residual virus activity in female compared with male participants (spontaneous RNA production by single-copy assay and multiply-spliced HIV RNA transcripts), despite comparable levels of integrated DNA in male and female participants (9). In addition, in ex vivo stimulation assays performed on 
A

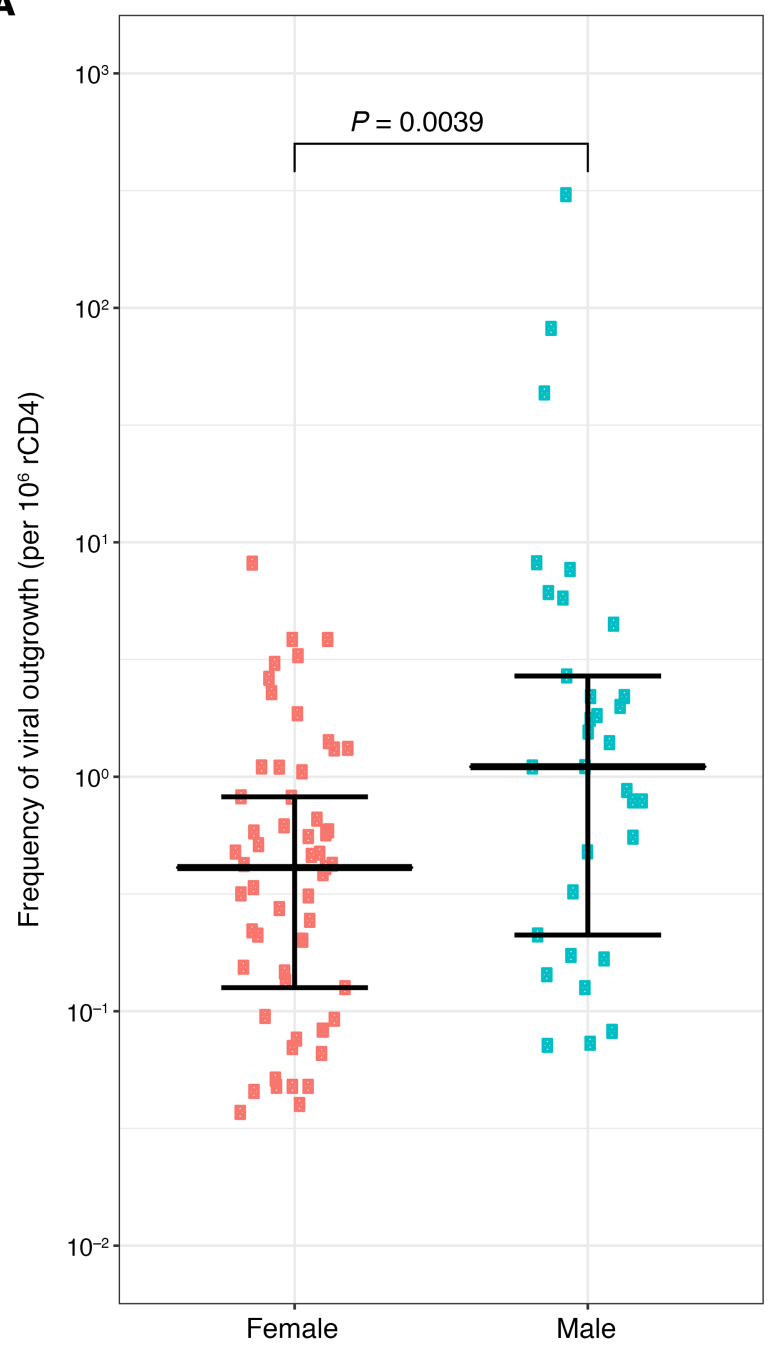

B

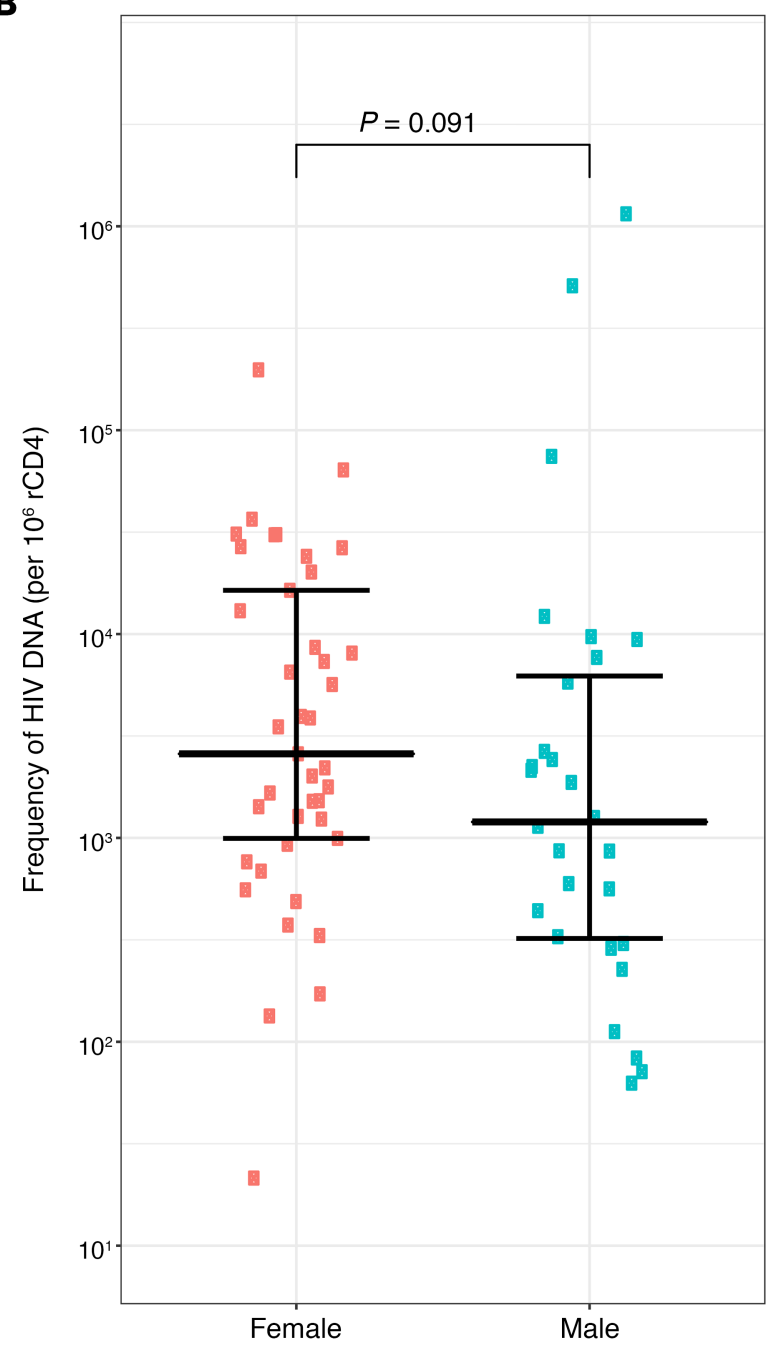

Figure 1. Differences in estimates of latent HIV-1 infection between virally suppressed female and male participants. (A) Frequency of resting CD4+ T cells ( $r C D 4$ ) that produce replication-competent virus when stimulated ex vivo by the QVOA (females $=57$, males $=33$ ). (B) Frequency of $r C D 4$ that contain HIV-1 gag DNA (females $=42$, males $=28$ ). Both reported per $10^{6} \mathrm{rCD} 4$. Adjusted analysis controls for age, pre-ART viral load, nadir CD4+ $T$ cell count, duration of ART, instances of transiently detectable viremia (proportion of on-ART viral loads $>400$ copies $/ \mathrm{mL}$ ), and CD4+ $4^{+}$cell count at the time of QVOA blood draw. Mann-Whitney $U$ test and multivariable linear regression were used. Median IUPM and interquartile range are presented. ART, antiretroviral therapy; QVOA, quantitative viral outgrowth assay.

a subset of this North American cohort (males $=6$ and females $=6$ ), female participants produced lower levels of multiply-spliced HIV RNA (21). These studies did not directly interrogate the replication-competent reservoir, and our results here demonstrate that the findings of differences in RNA transcription are consistent with differences in production of replication-competent virus between females and males.

We suggest 2 possible explanations for these findings: (a) a higher proportion of integrated proviruses are defective in females compared with males, and/or (b) there is a lower probability of proviral reactivation after ex vivo $\mathrm{T}$ cell stimulation in females compared with males. The first hypothesis is born out of the observation that the vast majority of HIV-1 proviruses (approximately 90\%) are defective owing to internal deletions, insertions, inversions, and APOBEC3F/G-induced hypermutation (19). If a larger proportion of proviruses were defective in females, the reduced QVOA viral outgrowth observed in females in this study would truly represent a smaller replication-competent reservoir. One prior study suggested that females have higher levels of hypermutation, but this finding warrants further investigation (22). Alternatively, females may have the same number of cells with replication-competent virus, but these cells may not reactivate as readily ex vivo. Previous studies have shown that not all replication-competent proviruses are reactivated with a single-round of $\mathrm{T}$ cell stimulation, and that multiple rounds of stimulation will continue to activate additional proviruses (23). Therefore, it is 
Table 2. Coefficients of univariate and stepwise linear regressions of reservoir outgrowth $\left(\log _{10}\right.$ IUPM) from resting CD4+ $T$ cells on demographic, clinical, and immunological covariates in women and men

\begin{tabular}{|c|c|c|c|c|}
\hline \multirow[t]{2}{*}{ Characteristic } & \multicolumn{2}{|c|}{ Univariate regression $(95 \% \mathrm{Cl})$} & \multicolumn{2}{|c|}{ Stepwise regression $(95 \% \mathrm{Cl})$} \\
\hline & $\begin{array}{l}\text { Women } \\
(n=57)\end{array}$ & $\begin{array}{c}\text { Men } \\
(n=33)\end{array}$ & $\begin{array}{c}\text { Women } \\
(n=29) \text { adj. } R^{2}=0.27\end{array}$ & $\begin{array}{c}\text { Men } \\
(n=10) \text { adj. } R^{2}=0.66\end{array}$ \\
\hline Age (per yr) & $-0.03^{A}(-0.05,-0.01)$ & $0.01^{A}(-0.04,0.07)$ & - & - \\
\hline $\begin{array}{l}\left.\text { Pre-ART viral load (per } \log _{10} \text { copy } / \mathrm{mL}\right) \text {; } \\
\text { women }(n=47) \text {, men }(n=28)\end{array}$ & $0.07(-0.15,0.29)$ & $0.16(-0.22,0.53)$ & $0.33(0.08,0.58)$ & $0.43(-\mathrm{d} 0.30,1.17)$ \\
\hline Nadir CD4+ ${ }^{+}$cell count (per 100 cells $/ \mu \mathrm{L}$ ) & $0.10^{A}(0.00,0.21)$ & $-0.10(-0.35,0.14)$ & - & \\
\hline $\begin{array}{l}\mathrm{CD4}^{+} / \mathrm{CD}^{+} \mathrm{T} \text { cell ratio at QVOA } \\
\text { (per } 0.1 \text { proportion increase) }\end{array}$ & $0.02(-0.30,0.74)$ & $-0.13^{A}(-0.23,-0.03)$ & & - \\
\hline $\begin{array}{l}\mathrm{PD}^{+}{ }^{+} \mathrm{CD} 4^{+} \mathrm{T} \text { cells (per } 1 \% \mathrm{PD}^{+} \mathrm{CD} 4^{+} \\
\mathrm{T} \text { cells); women }(n=34), \text { men }(n=13)\end{array}$ & $0.004(-0.009,0.016)$ & $0.040(0.004,0.072)$ & & $0.05(0.01,0.10)$ \\
\hline $\begin{array}{l}\text { IL-2 } 2^{+} \mathrm{CD}^{+} \text {T cells (per } 1 \% \text { IL-2+ CD4 }{ }^{+} \\
\text {T cells); women }(n=34) \text {, men }(n=13)\end{array}$ & $0.027^{A}(0.000,0.054)$ & $-0.036(-0.106,0.041)$ & - & \\
\hline $\begin{array}{l}\mathrm{TNF}^{+} \mathrm{CD}^{+} \mathrm{T} \text { cells }\left(\text { per } 1 \% \mathrm{TNF}^{+} \mathrm{CD}^{+}\right. \\
\text {T cells); women }(n=34), \text { men }(n=13)\end{array}$ & $0.018(0.000,0.035)$ & $-0.018(-0.052,0.017)$ & $0.01(-0.00,0.03)$ & \\
\hline
\end{tabular}

also possible that females have the same "size" of intact reservoir as males, but that the QVOA underestimates this size to a greater extent in females compared with males. In support of this later hypothesis, estrogen receptor-1 (ESR-1) has been shown to be able to silence HIV-1 provirus transcription in the presence of the female sex-hormone $\beta$-estradiol $(24,25)$, whereas selective estrogen receptor modulators, which inhibit estrogen activity, enhance reactivation in response to latency reversal agents (i.e., vorinostat, IL-15, and TNF) (21). Thus, it is possible that sex-specific features of transcriptional control can affect HIV-1 latency reversal. The QVOA is a gold standard for measuring changes in replication-competent reservoir size, and, therefore, the possibility of sex-based differences in the readout of this assay warrants further exploration. The question of whether females truly have fewer $\mathrm{rCD} 4$ harboring replication-competent virus or if their cells are less readily reactivated (or a combination of both) could be answered by detailed single-genome sequencing or targeted amplification strategies to measure the proportion of proviruses that are intact. However, single-genome level sequencing is not feasible for the number of participants needed to examine this question, and the intact proviral DNA assay (IPDA), designed to measure this exact question, has not yet been validated for non-B HIV-1 subtypes (26).

Our results demonstrate that correlates of replication-competent reservoir size also differ between men and women. Reservoir size correlated negatively with time on ART among both men and women, consistent with previous studies documenting slow decay of the reservoir during suppressive ART $(2,3)$. However, in men, immune parameters were also found to be important predictors of reservoir size, including a positive association with $\mathrm{PD} 1^{+} \mathrm{CD} 4^{+} \mathrm{T}$ cells. $\mathrm{PD} 1$ is a negative regulator of $\mathrm{T}$ cells, and its expression is associated with immune exhaustion and dysfunction (27). $\mathrm{CD} 4^{+} \mathrm{T}$ cells expressing $\mathrm{PD} 1$ have also been reported to be more likely to contain HIV-1 provirus, and that PD1 engagement inhibits viral reactivation (28). In light of these findings, PD1 agonists are currently being actively explored to augment latency reversal as part of cure strategies; however, to date, the vast majority of participants in the studies linking PD1 and latency have been male. Our findings may call into question the efficacy of PD1 agonists in HIV-1 cure strategies for female patients. In a similar way, sex differences in the efficacy of anti-PD1 antibodies for cancer immunotherapy have also been reported, with females gaining less benefit (29). Further research is warranted to assess the link between PD1 expression and HIV-1 latency in females.

An additional finding from our study is that, despite having similar nadir $\mathrm{CD} 4^{+} \mathrm{T}$ cell counts and having been on therapy for the same length of time, female participants had higher $\mathrm{CD} 4^{+} / \mathrm{CD} 8^{+} \mathrm{T}$ cell ratios 


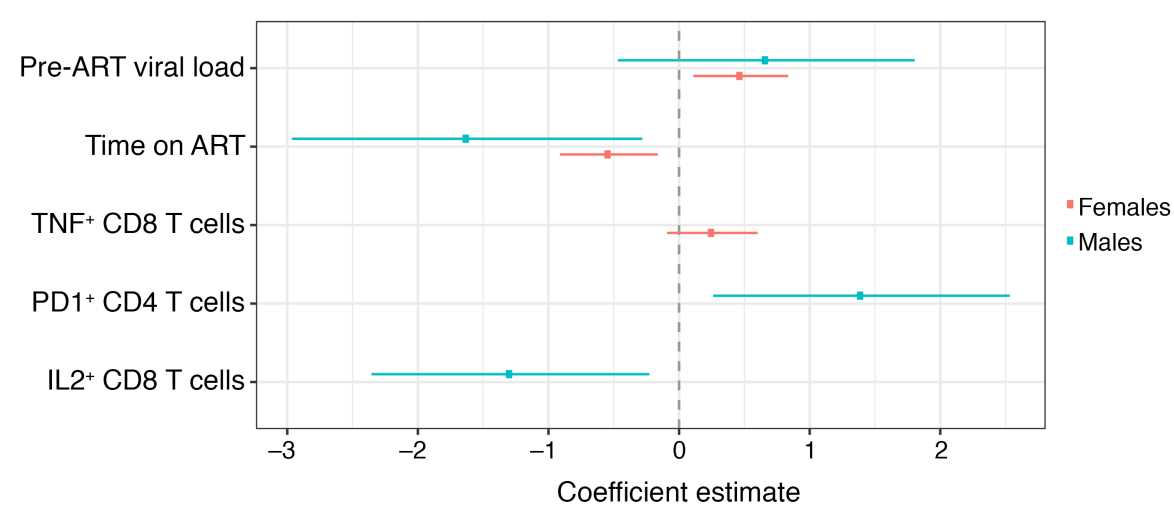

Figure 2. Multivariate regression coefficients and $95 \% \mathrm{Cl}$ for associations between clinical and immunological parameters that best predict reservoir outgrowth from resting $C D 4^{+}$T cells $\left(\log _{10}\right.$ IUPM) in female and male participants, as selected using stepwise regression (Table 2). Females (red, $n=29$ ); males (blue, $n=10$ ). IUPM, infectious units per million cells.

and $\mathrm{CD} 4^{+} \mathrm{T}$ cell counts than male participants, which is consistent with other reports (20). $\mathrm{CD} 4^{+} / \mathrm{CD} 8^{+} \mathrm{T}$ cell ratio has been associated with immune activation/exhaustion and non-AIDS mortality in individuals on ART (30). Further research is warranted to determine if the lower $\mathrm{CD} 4^{+} / \mathrm{CD} 8^{+} \mathrm{T}$ cell ratios observed in males in this and other studies are associated with sex-based differences in risk of non-AIDS mortality.

A significant strength of this study is that the HIV-1 epidemic in Rakai, Uganda, is generalized, as opposed to being localized in specific risk groups that vary by sex, as is often the case in North America. Men and women in our cohort were, therefore, well matched, with predominately heterosexual transmission and similar demographics, social determinants of health, and access to HIV-1 care. However, this study has several limitations. We had limited data on hormonal contraception use over the course of HIV-1 infection and did not ask women about their menstrual cycle or menopause status. As long-term suppressive ART significantly reduces HIV-specific CD8 ${ }^{+} \mathrm{T}$ cell responses, it was not possible to examine associations between these responses and QVOA reservoir outgrowth. Sample sizes were smaller than ideal for use of stepwise selection; however, models were statistically satisfactory with residuals randomly scattered between -1 and 1 , and no detrimental multicollinearity detected (variance inflation factors of all predictors were $<2$ ). Finally, as discussed, we were unable to use sequencing or ddPCR-based techniques to quantify intact and defective proviruses in this study; therefore, adaptation of the IPDA to nonsubtype B viruses is urgently needed to enable high-throughput intact provirus quantification.

These data highlight that the latent viral reservoir may be fundamentally different in males and females and raise the possibility that reservoir reactivation may differ between males and females. Females are generally underrepresented in HIV-1 cure research, leaving uncertainty as to the generalizability of results to all people living with HIV. Researchers should make a greater effort to increase participation of females in HIV-1 research and to present data stratified by sex.

\section{Methods}

Study participants. Ninety HIV-1-infected adults ( $\geq 18$ years) were enrolled through the Rakai Health Sciences Program in Uganda. Participants were on ART and had been virally suppressed for $\geq 1$ year ( 2 historical viral loads $<40$ copies $/ \mathrm{mL}$, obtained 10-18 months apart, with no intervening detectable result).

Sample and clinical data collection. Pre-ART CD4 ${ }^{+} \mathrm{T}$ cell counts, post-ART viral loads, and ART regimens were extracted from clinical records. Additional demographic data were available on a subset of participants enrolled in the Rakai Community Cohort Study (31), including estimated date of HIV seroconversion $(n=32)$, hormonal contraception use $(n=48)$, and pre-ART viral loads $(n=75)$.

Blood (180 mL) was separated for T cell counting, plasma HIV-1 RNA detection (viral load), and PBMC cryopreservation. $\mathrm{T}$ cell counts and viral loads were performed at all study visits (Supplemental Methods). PBMCs were isolated using density-gradient centrifugation and cryopreserved in 10\% DMSO. For 43 individuals, cryopreserved PBMCs were used for QVOA and total HIV DNA quantification ( $g a g$ qPCR). For the 
other 47 participants, $1 \times 10^{7}$ cryopreserved PBMCs were obtained for immune cell characterization, and all remaining cells were dedicated to QVOA. For these participants, additional cells for total HIV DNA quantification were obtained at a second blood draw performed within 10-14 months. Plasma HIV RNA quantification was repeated at the second blood draw, and in all cases plasma viral loads remained below the limit of detection ( $<40$ copies/mL).

Reservoir and immune characterization. rCD4 isolation, QVOA, total HIV DNA measurement (qPCR), and HIV-1 subtyping were performed as previously described (additional details in Supplemental Methods) (32-34). Immunological assessments were performed on individuals for whom stored PBMCs $(n=47)$ and plasma samples $(n=62)$ were available. An electrochemiluminescent detection system was used to assay the following soluble immune molecules in plasma samples (Meso Scale Discovery): IFN2 $\alpha$, IL-10, IL-15, IL-6, IL-7, MIG/CXCL9, MIP3 $\alpha$ /CCL19, MIP3 $\beta$ /CCL20, D-dimer, sCD14, IP10, CRP, and CCL21. Immune cell characterization was performed using 2 flow cytometry panels: 1 to assess $\mathrm{CD} 4^{+} \mathrm{T}$ cell subsets and activation status $\left(\mathrm{CD}^{+}, \mathrm{CD}^{+}, \mathrm{CD} 45 \mathrm{RO}, \mathrm{CD} 28\right.$, CCR7, CD57, HLA-DR, CD38, CD69, Ki-67, FoxP3, and CD25) and 1 to assess $\mathrm{T}$ cell effector function, including markers of $\mathrm{T}$ cell exhaustion (CD3 ${ }^{+}$, $\mathrm{CD}^{+}, \mathrm{CD}^{+}, \mathrm{CD} 107 \mathrm{a}$, perforin, IFN- $\gamma$, TNF, IL-2, Tim3, CTLA4, and PD1). Both panels included a viability dye. Additional details on immune characterization methods and representative flow cytometry gating are provided in the Supplemental Methods and Supplemental Figure 3. Immune phenotyping and reservoir quantification assays were performed by investigators blinded to participant demographics, including biological sex.

Statistics. Demographic, clinical, and immunological characteristics were compared between men and women using Mann-Whitney $U$ test. Clinical variables were defined as follows: pre-ART viral load is the last viral load measurement before ART initiation, nadir $\mathrm{CD} 4^{+}$is the lowest $\mathrm{CD} 4^{+} \mathrm{T}$ cell count recorded before ART initiation, time on ART is the time between ART initiation and sample time point, and viremic time is the time from estimated date of seroconversion to initiation of ART. Dates of seroconversion were estimated as the midpoint between the last seronegative and the first seropositive HIV-1 test results available. The proportion of viral loads $>400$ copies $/ \mathrm{mL}$ since initial viral suppression summarizes instances of transiently detectable viremia during ART. Hormonal contraception use is described by (a) self-reported use at the time of study visit and (b) the estimated proportion of time using hormonal contraception from ART initiation to study visit.

Mann-Whitney $U$ test was used to compare differences in reservoir size (IUPM and total HIV DNA) between men and women, followed by multivariate analyses to control for covariates (nadir CD4 T cell count, pre-ART VL, time on ART, instances of on-ART transiently detectable viremia, and $\mathrm{CD}^{+} / \mathrm{CD}^{+}$ratio). Characteristics associated with reservoir size were determined using univariate regression analyses, stratified by sex. The strongest predictors of QVOA reservoir outgrowth in each sex were identified by stepwise regression, including time on ART and pre-ART viral load (determined a priori from previous studies; ref. 20) (1), and variables associated with IUPM for that sex in univariate analysis $(P<0.1)$. Transformations of outcomes and covariates were conducted to satisfy model assumptions: soluble immune analytes, pre-ART viral load, time on ART, IUPM, and total HIV DNA were $\log _{10}$ transformed. Analytes detectable in $<50 \%$ of participants were treated as binary outcomes (IL-10, MIP3A). Statistical analyses were conducted using R (version 3.5.2), and all tests were 2 sided with $\alpha=0.05$. A $P$ value of less than 0.05 was considered significant.

Study approval. All participants provided written informed consent, and ethical approval was obtained by the Institutional Review Boards at Johns Hopkins, the Uganda Virus Research Institute, the Uganda National Council for Science and Technology, and the National Institute of Allergy and Infectious Diseases.

\section{Author contributions}

All authors meet the criteria for authorship in the ICMJE Recommendations. JLP, ADR, and TCQ designed the study and interpreted findings. JLP lead immunology laboratory work, performed flow cytometry assays, compiled databases, and lead data analysis and manuscript preparation. AAC and JL performed viral outgrowth assays. KY performed data analysis and prepared the initial draft of the manuscript. SJR and JK contributed to study design and oversaw participant enrolment and sample collection. TK and PB contributed to study visit procedures, data collection, and biological sample processing. SD contributed to study design and oversaw study visits. KJK performed total HIV DNA quantification. KS performed soluble immune analyte quantification. CM and ADR oversaw HIV sequencing of outgrowth viruses for subtype determination. ES contributed to data interpretation and manuscript preparation. YHC assisted with statistical analyses. All authors have read the manuscript and contributed to its intellectual content. 


\section{Acknowledgments}

This work was supported by the Division of Intramural Research, National Institute of Allergy and Infectious Diseases, and Gilead HIV Cure Grants Program (90072171). Janet Siliciano and Robert Siliciano (John's Hopkins University School of Medicine, Baltimore, Maryland, USA) assisted with quantitative viral outgrowth assays.

Address correspondence to: Thomas C. Quinn, 600 N. Wolfe Street; Rangos Building Suite 531; Baltimore, Maryland 21287, USA. Phone: 410.955.7635; Email: tquinn2@jhmi.edu.

1. Finzi D, et al. Latent infection of $\mathrm{CD}^{+} \mathrm{T}$ cells provides a mechanism for lifelong persistence of HIV-1, even in patients on effective combination therapy. Nat Med. 1999;5(5):512-517.

2. Crooks AM, et al. Precise quantitation of the latent HIV-1 reservoir: implications for eradication strategies. J Infect Dis. 2015;212(9):1361-1365.

3. Siliciano JD, et al. Long-term follow-up studies confirm the stability of the latent reservoir for HIV-1 in resting CD4 ${ }^{+} \mathrm{T}$ cells Nat Med. 2003;9(6):727-728.

4. Johnston RE, Heitzeg MM. Sex, age, race and intervention type in clinical studies of HIV cure: a systematic review. AIDS Res Hum Retroviruses. 2015;31(1):85-97.

5. Sterling TR, Vlahov D, Astemborski J, Hoover DR, Margolick JB, Quinn TC. Initial plasma HIV-1 RNA levels and progression to AIDS in women and men. N Engl J Med. 2001;344(10):720-725.

6. Meier A, et al. Sex differences in the Toll-like receptor-mediated response of plasmacytoid dendritic cells to HIV-1. Nat Med. 2009;15(8):955-959.

7. Chang JJ, et al. Higher expression of several interferon-stimulated genes in HIV-1-infected females after adjusting for the level of viral replication. J Infect Dis. 2013;208(5):830-838.

8. Stevenson EM, et al. OP 4.6 Dynamics of HIV-specific T cells on long-term ART differ by antigen recognised and by sex. J Virus Erad. 2019;5(supp1_3):1-58.

9. Scully EP, et al. Sex-based differences in human immunodeficiency virus type 1 reservoir activity and residual immune activation. J Infect Dis. 2019;219(7):1084-1094.

10. Mathad JS, et al. Sex-related differences in inflammatory and immune activation markers before and after combined antiretroviral therapy initiation. J Acquir Immune Defic Syndr. 2016;73(2):123-129.

11. Cuzin L, et al. Levels of intracellular HIV-DNA in patients with suppressive antiretroviral therapy. AIDS. 2015;29(13):16651671.

12. Fourati S, et al. Factors associated with a low HIV reservoir in patients with prolonged suppressive antiretroviral therapy. $J$ Antimicrob Chemother. 2014;69(3):753-756.

13. Le CN, et al. Time to viral rebound and safety after antiretroviral treatment interruption in postpartum women compared with men. AIDS. 2019;33(14):2149-2156.

14. Borges AH, et al. Factors associated with D-dimer levels in HIV-infected individuals. PLoS One. 2014;9(3):e90978.

15. Chomont N, et al. HIV reservoir size and persistence are driven by T cell survival and homeostatic proliferation. Nat Med. 2009;15(8):893-900.

16. Vandergeeten C, et al. Interleukin-7 promotes HIV persistence during antiretroviral therapy. Blood. 2013;121(21):4321-4329.

17. Grund B, et al. Relevance of interleukin-6 and D-Dimer for serious non-AIDS morbidity and death among HIV-positive adults on suppressive antiretroviral therapy. PLoS One. 2016;11(5):e0155100.

18. Cameron PU, et al. Establishment of HIV-1 latency in resting CD4 ${ }^{+} \mathrm{T}$ cells depends on chemokine-induced changes in the actin cytoskeleton. Proc Natl Acad Sci U S A. 2010;107(39):16934-16939.

19. Bruner KM, et al. Defective proviruses rapidly accumulate during acute HIV-1 infection. Nat Med. 2016;22(9):1043-1049.

20. Bachmann N, et al. Determinants of HIV-1 reservoir size and long-term dynamics during suppressive ART. Nat Commun. 2019;10(1):3193.

21. Das B, et al. Estrogen receptor-1 is a key regulator of HIV-1 latency that imparts gender-specific restrictions on the latent reservoir. Proc Natl Acad Sci U S A. 2018;115(33):E7795-E7804.

22. de Lima-Stein ML, et al. In vivo HIV-1 hypermutation and viral loads among antiretroviral-naive Brazilian patients. AIDS Res Hum Retroviruses. 2014;30(9):867-880.

23. Ho YC, et al. Replication-competent noninduced proviruses in the latent reservoir increase barrier to HIV-1 cure. Cell. 2013;155(3):540-551.

24. Szotek EL, Narasipura SD, Al-Harthi L. 17 $\beta$-Estradiol inhibits HIV-1 by inducing a complex formation between $\beta$-catenin and estrogen receptor $\alpha$ on the HIV promoter to suppress HIV transcription. Virology. 2013;443(2):375-383.

25. Asin SN, Heimberg AM, Eszterhas SK, Rollenhagen C, Howell AL. Estradiol and progesterone regulate HIV type 1 replication in peripheral blood cells. AIDS Res Hum Retroviruses. 2008;24(5):701-716.

26. Bruner KM, et al. A quantitative approach for measuring the reservoir of latent HIV-1 proviruses. Nature. 2019;566(7742):120-125.

27. Day CL, et al. PD-1 expression on HIV-specific T cells is associated with T-cell exhaustion and disease progression. Nature. 2006;443(7109):350-354.

28. Fromentin R, et al. PD-1 blockade potentiates HIV latency reversal ex vivo in $\mathrm{CD}^{+} \mathrm{T}$ cells from ART-suppressed individuals. Nat Commun. 2019;10(1):814.

29. Wang S, Cowley LA, Liu XS. Sex differences in cancer immunotherapy efficacy, biomarkers, and therapeutic strategy. Molecules. 2019;24(18):E3214.

30. Serrano-Villar S, et al. HIV-infected individuals with low CD4/CD8 ratio despite effective antiretroviral therapy exhibit altered 
T cell subsets, heightened CD8+ T cell activation, and increased risk of non-AIDS morbidity and mortality. PLoS Pathog. 2014;10(5):e1004078.

31. Grabowski MK, et al. HIV prevention efforts and incidence of HIV in Uganda. N Engl J Med. 2017;377(22):2154-2166.

32. Prodger JL, et al. Reduced frequency of cells latently infected with replication-competent human immunodeficiency virus-1 in virally suppressed individuals living in Rakai, Uganda. Clin Infect Dis. 2017;65(8):1308-1315.

33. Massanella M, Gianella S, Lada SM, Richman DD, Strain MC. Quantification of total and 2-LTR (Long terminal repeat) HIV DNA, HIV RNA and Herpesvirus DNA in PBMCs. Bio Protoc. 2015;5(11):e1492.

34. Laird GM, Rosenbloom DI, Lai J, Siliciano RF, Siliciano JD. Measuring the frequency of latent HIV-1 in resting CD4+ T cells using a limiting dilution coculture assay. Methods Mol Biol. 2016;1354:239-253. 